\title{
Modelling of cycling of lithium battery with microporous carbon electrode
}

\author{
D.Portnyagin \\ Institute for Condensed Matter Physics of the National Academy of Sciences of Ukraine, \\ 1 Svientsitskii Str., 79011 Lviv, Ukraine
}

Received April 23, 2007, in final form September 17, 2008

\begin{abstract}
Charge/discharge cycles of lithium cell with microporous carbon electrode under potentiodynamic control have been modelled. Predictions of the models with variable and constant diffusion coefficient neglecting the electric field inside the particle (CPM, DFM) are compared to the predictions of the models with variable and constant diffusion coefficient in which electrostatic interaction inside the particles of carbon electrode (CPME, DFME) is taken into account. There is observed a considerable difference between both. Electrostatic interactions of lithium ions with each other and the charge distributed inside the particle promote intercalation during the discharge of the cell and deintercalation during the charge. The dependance of the effect of hysteresis during the cycling of the cell on the rate of change of the applied voltage is studied. The larger is the speed of change of the applied voltage the more effective is hysteresis. We have also obtained concentration profiles at different stages of charge/discharge process.
\end{abstract}

Key words: lithium battery, porous electrode, potentiometry

PACS: 82.47.Aa, 82.45.Gj, 82.45.Fk, 82.45.-h, 82.20.Wt

\section{Introduction}

The recent developments appearing in the market of mobile phones, laptop computers and other portable devices and electric vehicles evoke the demand for high energy density portable power sources. In portable batteries lithium often serves as a cathode material due to its low electronegativity. Anodes are made of porous materials due to their large surface area associated with high energy storage. Mathematical simulations of charge/discarge processes make it possible to optimize a battery in order to obtain a higher performance. This can also be helpful in analysing these processes to gain a deeper insight into the nature and courses of phenomena that occur during the cycling of these devices. Recently, simulations of intercalation of lithium into the structure of a porous electrode have been reported by several authors [1-3]. It is widely held that the main driving force at the operation of the battery is diffusion and that the transport of ions across the electrode is governed by Fick's second law. The present paper presents an improvement to this approach by taking into account electrostatic interaction between ions as well as the distribution of charge in the bulk of porous electrode. Comparison of the predictions of the diffusive model and the more realistic electrodynamic one suggests that there is a certain discrepancy between them.

\section{Basic considerations. Cylindrical particles}

We study the cycling of lithium battery under potentiodynamic control. In our research we heavily rely upon the data from [2]. The battery consists of lithium foil, porous separator of thickness $L_{\mathrm{s}}=25 \mu \mathrm{m}$, porous carbon electrode of thickness $L_{1}=125 \mu \mathrm{m}$ made of either cylindrical or spherical particles of radius $R_{\mathrm{s}}=3.5 \mu \mathrm{m}$, and current collector (see figure 1). The battery is immersed in $1 \mathrm{M}$ solution of $\mathrm{LiClO}_{4}$ in propylene carbonate.

The applied potential changes linearly with time and is given by

$$
U_{\mathrm{app}}=U_{0}+\omega t,
$$


where $U_{0}$ is the initial applied potential, $\omega$ is the sweep rate, $t$ is time. At sweep rates of 10,5 and $1 \mathrm{mV} / \mathrm{s}$ the battery was discharged from its initial state to $0.075 \mathrm{~V}$, then it was charged to $1.5 \mathrm{~V}$, and finally it was again discharged to $0.075 \mathrm{~V}$. These steps were repeated twice to reach a periodic state. The periodic state is the state, at which the results are uniform and sustained during consecutive cycles, when cycled under the same conditions.

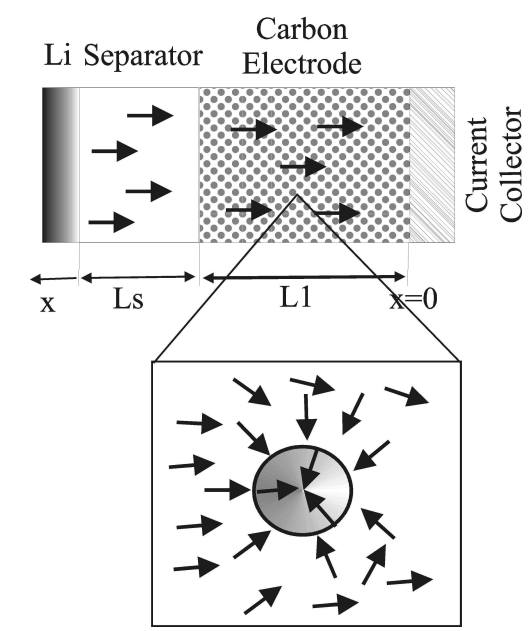

Figure 1. Schematic diagram of the lithium cell. Arrows show the flux of lithium ions.

During the discharge of the battery, lithium is dissolved into lithium ions from the negative electrode, migrates through the separator and finally intercalates into the carbon electrode. During the charge the reverse process takes place (see figure 2,3 ). We neglect the expansion and contraction of the electrodes. There exist two approaches for modelling the lithium insertion into the particle, both of which lead to the solution of the diffusion equation in a particle. In the first approach, the driving force is the gradient of concentration while the diffusion coefficient remains constant. However, it has been reported that there is a strong dependence of the diffusion coefficient on concentration due to the 'lithium ion'-'lithium ion' interactions inside the particle, which cannot be ignored to obtain good agreement with experimental data. In the second approach, Verbrugge and Koch [4] considered the gradient of the chemical potential of the inserted lithium ions as the driving force.

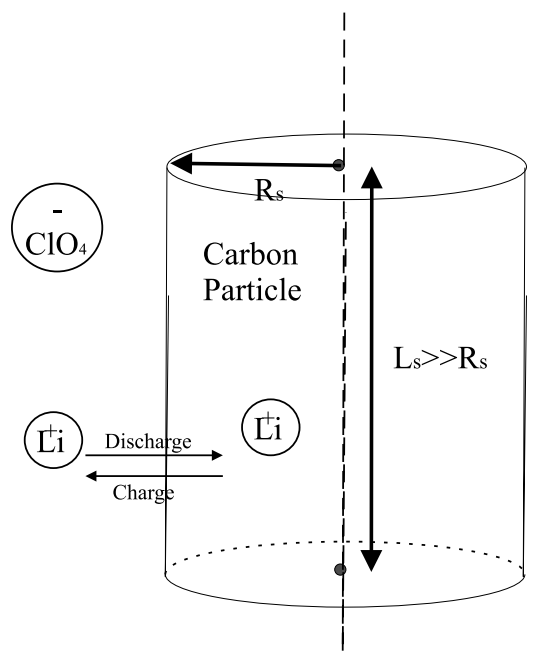

Figure 2. Lithium intercalates into the carbon fiber.

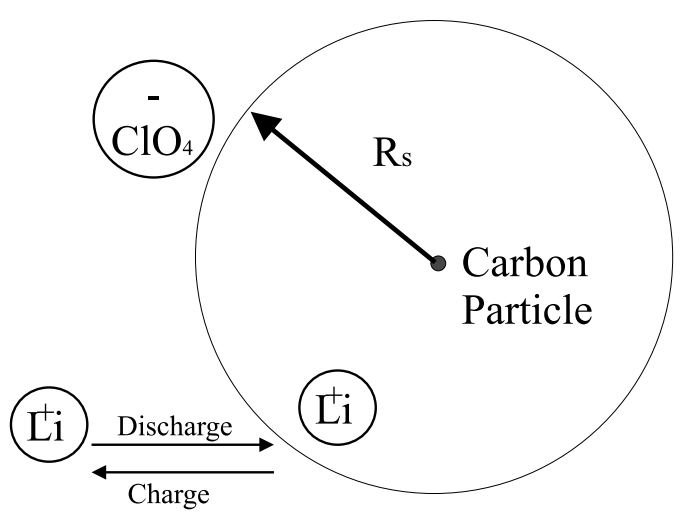

Figure 3. Lithium intercalates into spherical particle. 
In the present section we consider cylindrical particles with the ratio of length to radius sufficiently large, for which the concentration of lithium inside the particle is a function only of radial distance, governed by the equation

$$
\begin{aligned}
\frac{\partial y}{\partial \tau} & =\frac{1}{R} \frac{\partial}{\partial R}\left(R f(y) \frac{\partial y}{\partial R}\right) \\
y & =y_{0} \quad \text { at } \tau=0, \quad \forall R, \\
\frac{\partial y}{\partial R} & =0 \text { at } R=0, \quad \forall \tau, \\
\frac{\partial y}{\partial R} & =-\frac{j_{n}^{+}}{D_{\mathrm{s}}} \frac{R_{\mathrm{s}}}{C_{\mathrm{s}, \max } f} \text { at } R=1, \quad \forall \tau,
\end{aligned}
$$

where $\tau=t D_{\mathrm{s}} / R_{\mathrm{s}}^{2}, y=C_{\mathrm{s}} / C_{\mathrm{s}, \max }, R=r / R_{\mathrm{s}}$; are dimensionless variables. $D_{\mathrm{s}}$ is the diffusion coefficient in the solid phase, assumed to be constant, $R_{\mathrm{S}}$ is the radius of the particle, $C_{s}$ is the concentration of lithium ions inside the particle, $C_{\mathrm{s}, \max }$ is the maximum concentration of lithium ions inside the particle, $f$ is the activity factor dependant on the intercalation fraction and calculated by Verbrugge and Koch [4], $j_{n}^{+}$is the flux of lithium ions at the surface of the particle. The initial value of $y$ is equal to 0.01 . The flux of lithium ions at the surface of the particle is equal to the electrochemical reaction rate per unit of surface area of the particle as given by a Butler-Volmer reaction rate expression

$$
j_{n}^{+}=K\left(C\left(1-\left.y\right|_{R=1}\right)\right)^{\beta-1}\left(\left.y\right|_{R=1}\right)^{\beta}\left\{\exp \left[\frac{(1-\beta) F}{\Re T}(\eta-U)\right]-\exp \left[\frac{-\beta F}{\Re T}(\eta-U)\right]\right\},
$$

where $C$ is the concentration of the electrolyte, $K$ is the reaction rate constant, $\beta$ is the symmetry factor taken to be 0.5 , reflecting a strongly solvated ion, $F$ is the Faraday constant, $\Re$ is universal gas constant, $T$ is temperature, $\eta$ is the potential between solid phase and electrolyte, and $U$ represents the open-circuit cell potential with respect to a metallic lithium electrode which is evaluated at the surface of the particle where the electrochemical reaction takes place and which is given by [4]

$$
U=U_{\mathrm{s}}+\frac{\Re T}{F} \ln \left(\frac{1-\left.y\right|_{R=1}}{\left.y\right|_{R=1}}\right)-\sum_{s=2}^{7} \frac{\Omega_{\mathrm{s}}}{F} s\left(\left.y\right|_{R=1}\right)^{s-1} \quad \text { for } \quad 0<\left.y\right|_{R=1}<0.985,
$$

where $U_{\mathrm{s}}$ is the standard cell potential with respect to a metallic lithium electrode, and $\Omega_{\mathrm{s}}$ are the self-interaction energies. This expression is obtained by least square polynomial regression of the experimental curve open-circuit potential $U$ vs. concentration on the surface of the particle $\left.y\right|_{R=1}$ (see $[4]$ ). $\Omega_{\mathrm{s}}$ describes the deviation from the ideal behavior due to $s$-nary (i. e., binary, ternary, ...) interactions between ions, in the expression for free energy. We restrict ourselves to $s=7$, in all the other respects formulae (5), (7) are exact. We take the activity coefficient

$$
f=1
$$

for a purely diffusive model, and

$$
f=\left(1+\frac{\mathrm{d} \ln \gamma_{+}}{\mathrm{d} \ln y}\right)=1+\sum_{s=2}^{7} \frac{\Omega_{\mathrm{s}}}{\Re T} s(s-1)\left(y^{s-1}-y^{s}\right)
$$

for a chemical potential model [4] (at low lithium concentrations, $f$ increases with the lithium ion concentration increasing due to repulsive effects, takes on its maximum at $y=0.2$, and decreases with the lithium ion concentration increasing due to a low ion mobility at higher concentrations). Our amendment to the aforementioned models consists in adding the current coursed by electric field to the righthand side of equation (1).

$$
\frac{\partial y}{\partial t}=\frac{D_{\mathrm{s}}}{R_{\mathrm{s}}^{2}} \frac{1}{R} \frac{\partial}{\partial R}\left(R f(y) \frac{\partial y}{\partial R}\right)-\frac{1}{F C_{\max , \mathrm{s}}} \operatorname{div}(\sigma(y) E),
$$


where $E$ is the electric field, $\sigma$ is the ionic conductivity given by Einstein relation

$$
\sigma=y C_{\max , \mathrm{s}} N_{\mathrm{a}} D_{\mathrm{s}} \mathrm{e}^{2} / k T
$$

$k$ is Boltzman constant, e is elementary charge, $N_{\mathrm{a}}$ is Avogadro number, and here $\operatorname{div}(A(R))=$ $\frac{1}{R} \frac{\partial}{\partial R}(R A(R))$.

In the first approximation we assume that the current of positive ions through the surface of the particle is entirely due to the uniform distribution within the particle of negative charge, which carbon, being more electronegative, draws from lithium, as well as due to the distribution of the charge caused by imposed external electric field. However, X-ray photoelectron spectroscopy (XPS) proved [5] that after insertion, lithium retains only a fraction of the positive charge $+\delta$, while carbon takes a negative charge $-\delta$. Therefore, we add the term associated with the nonuniform distribution of lithium ions to the distribution of charge in the bulk of the particle. This results in

$$
\operatorname{div}(E)=\frac{2}{R_{\mathrm{s}} \sigma_{\mathrm{eff}, 1}} j_{n}^{+}-\delta \frac{F C_{\mathrm{max}, \mathrm{s}}}{\varepsilon_{0}}\left(y_{\mathrm{avr}}-y\right)
$$

where $\sigma_{\mathrm{eff}, 1}$ is the effective conductivity of electrolyte in the carbon electrode, $\varepsilon_{0}$ is the dielectric constant, $y_{\mathrm{avr}}=\int y \mathrm{~d} V / V=2 \int_{0}^{1} y R \mathrm{~d} R$ (or $=3 \int_{0}^{1} y R^{2} \mathrm{~d} R$ for spherical particles) is the average concentration of ions in the particle, $\delta$ is the delocalization factor which equals 1 when we have naked lithium ions and negative charge, drawn from lithium, uniformly spread over carbon sites, and equals 0 when negative charge is maximally localized on lithium ions. Within the framework of our model the first term in (9) is the density of a uniformly distributed charge that yields the current $j_{n}^{+}$on the surface of a particle. Herein we add the term associated with nonuniform distribution of lithium ions inside the particle, multiplied by the factor that characterizes the amount to which the electron cloud is drawn from lithium by a more electronegative carbon. The mean value of the second term is zero.

We shall refer to the insertion of lithium ions as a process given by the solution of (1)-(4) with $f$ given by (6) the (DFM) model, and with $f$ given by $(7)$ - the (CPM) model. We shall call the diffusion process described by (8), (2)-(4) with $f$ given by (6) the (DFME) model, and with $f$ given by (7) - the (CPME) model.

The ionic current across the carbon electrode $i_{2}$ is equal to the external current through the battery $i_{\text {total }}$ at the contact with separator, and is zero at the current collector. Between these two values the current is assumed to be distributed according to the equation:

$$
\frac{\partial i}{\partial x}=a F j_{n}^{+}
$$

where $a$ is the interfacial area of particles per unit volume of porous electrode, calculated by

$$
a=0.03 \cdot 2\left(1-\epsilon_{1}\right) / R s
$$

for the case of cylindrical particles, or by

$$
a=0.02 \cdot 3\left(1-\epsilon_{1}\right) / R s
$$

for spherical particles; $\epsilon_{1}$ is the porosity of carbon electrode. It appears quite obvious that after we have pressed and baked the carbon material, only a fraction of the particle's surface will be exposed to electrolyte, so we have introduced a suitable factor in the formula for the interfacial area. The equation for the concentration of the electrolyte in the solution phase of the carbon electrode is as follows:

$$
\epsilon_{k} \frac{\partial C}{\partial t}=\nabla\left(\epsilon_{k} D_{\mathrm{eff}, k} \nabla C\right)+a\left(1-t_{+}^{0}\right) j_{n}^{+}
$$

where $k=1, s$ (1 corresponds to electrode, $s$ to separator), $t_{+}^{0}$ is transfer number, $D_{\text {eff }, k}=\epsilon_{k}^{0.5} D$, $D$ is the diffusion coefficient of electrolyte, $C_{\text {initial }}=1000 \mathrm{~mol} / \mathrm{m}^{3}$. We impose on $C$ the following 
boundary conditions: $(i)$ that the flux of ions at lithium electrode is equal to the total current through the cell

$$
\left.\epsilon_{\mathrm{s}} D_{\mathrm{eff}, \mathrm{s}} \nabla C\right|_{x=L_{\mathrm{s}}+L_{1}}=i_{\text {total }} / F,
$$

(ii) that the flux of mass is continuous at the separator-electrode interface

$$
\left.\epsilon_{\mathrm{s}} D_{\mathrm{eff}, \mathrm{s}} \nabla C\right|_{x=L_{1}+0}=\left.\epsilon_{1} D_{\mathrm{eff}, 1} \nabla C\right|_{x=L_{1}-0},
$$

and (iii) that it is equal to zero at the current collector

$$
\left.\epsilon_{1} D_{\text {eff }, 1} \nabla C\right|_{x=0}=0 .
$$

\begin{tabular}{|c|c|}
\hline Parameter & Value \\
\hline$U_{0}$ & $0.91489 \mathrm{~V}$ \\
\hline$U_{\mathrm{s}}$ & $0.8170 \mathrm{~V}$ \\
\hline$\Omega_{2} / F$ & $0.9926 \mathrm{~V}$ \\
\hline$\Omega_{3} / F$ & $0.8981 \mathrm{~V}$ \\
\hline$\Omega_{4} / F$ & $-5.630 \mathrm{~V}$ \\
\hline$\Omega_{5} / F$ & $8.585 \mathrm{~V}$ \\
\hline$\Omega_{6} / F$ & $-5.784 \mathrm{~V}$ \\
\hline$\Omega_{7} / F$ & $1.468 \mathrm{~V}$ \\
\hline$C_{\mathrm{s}, \max }$ & $18,000 \mathrm{~mol} / \mathrm{m}^{3}$ \\
\hline$\beta$ & 0.5 \\
\hline$K$ & $3.28 \times 10^{-6} \mathrm{~mol}^{1 / 2} / \mathrm{m}^{1 / 2} \mathrm{~s}$ \\
\hline$K_{L i}$ & $4.1 \times 10^{-6} \mathrm{~mol}^{1 / 2} / \mathrm{m}^{1 / 2} \mathrm{~s}$ \\
\hline$C_{\text {initial }}$ & $1000 \mathrm{~mol} / \mathrm{m}^{3}$ \\
\hline$T$ & $298 \mathrm{~K}$ \\
\hline$y_{\text {initial }}$ & 0.01 \\
\hline$D$ & $2.6 \times 10^{-10} \mathrm{~m}^{2} / \mathrm{s}$ \\
\hline$D_{\mathrm{s}}$ & $1.0 \times 10^{-14} \mathrm{~m}^{2} / \mathrm{s}$ \\
\hline$t_{+}^{0}$ & 0.2 \\
\hline$\sigma_{\mathrm{eff}, k}$ & $\begin{array}{c}0.0001+\epsilon_{k}^{1.5} C^{0.855}\left(0.00179 \exp \left(-0.08(0.00083 C-0.6616)^{2}-\right.\right. \\
0.0010733 C+0.855))\end{array}$ \\
\hline$\sigma_{\mathrm{el}}$ & $100 \mathrm{~S} / \mathrm{m}$ \\
\hline$R_{s}$ & $3.5 \times 10^{-6} \mathrm{~m}$ \\
\hline$L_{\mathrm{s}}$ & $25 \times 10^{-6} \mathrm{~m}$ \\
\hline$L_{1}$ & $125 \times 10^{-6} \mathrm{~m}$ \\
\hline$k$ & $1.381 \times 10^{-23} \mathrm{~J} / \mathrm{K}$ \\
\hline$N_{\mathrm{a}}$ & $6.022 \times 10^{23} \mathrm{~mol}^{-1}$ \\
\hline$\Re$ & $8.314 \mathrm{~J} /(\mathrm{mol} \cdot \mathrm{K})$ \\
\hline$F$ & $96,487 \mathrm{C} / \mathrm{mol}$ \\
\hline$\varepsilon_{0}$ & $8.854 \times 10^{-12} \mathrm{C}^{2} /\left(\mathrm{N} \cdot \mathrm{m}^{2}\right)$ \\
\hline$e$ & $1.9 \times 10^{-19} \mathrm{C}$ \\
\hline$\delta$ & $2 \times 10^{-10}$ \\
\hline$\epsilon_{1}$ & 0.35 \\
\hline$\epsilon_{\mathrm{s}}$ & 0.55 \\
\hline
\end{tabular}

Table 1. Standard cell potential, interaction energies, model parameters for the carbon-lithium cell and physical constants.

The potential in the solution phase is (see [6])

$$
\nabla \phi_{1}=-\frac{i_{2}}{\sigma_{\mathrm{eff}, k}}+\frac{\Re T\left(1-t_{+}^{0}\right)}{F C} \nabla C,
$$


where $\sigma_{\text {eff }, k}$ is the effective conductivity of electrolyte given in table 1 . The potential in the solid phase of the electrode is

$$
\nabla \phi_{2}=-\frac{\left(i_{\text {total }}-i_{2}\right)}{\sigma_{\text {eff }}}
$$

where $\sigma_{\text {eff }}=\epsilon_{1}^{1.5} \sigma_{\mathrm{el}}$ is the effective conductivity of electrode. The local surface overpotential is given by

$$
\eta=\phi_{1}-\phi_{2}
$$

The applied potential of the cell is related to $\eta$ by

$$
U_{\mathrm{app}}=\left.\eta\right|_{x=L_{\mathrm{s}}+L_{1}}+\left(\phi_{1}-\phi_{2}\right)_{\mathrm{kin}}+\int_{x=0}^{x=L_{1}} \frac{\left[i_{\text {total }}-i_{2}(x)\right]}{\sigma_{\mathrm{eff}}}
$$

where $\left(\phi_{1}-\phi_{2}\right)_{\text {kin }}$ is given by kinetic expression (see [6])

$$
i_{\text {total }}=F K_{L i} C^{0.5}\left(\exp \left((0.5 F /(\Re T))\left(\phi_{1}-\phi_{2}\right)\right)-\exp \left(-(0.5 F /(\Re T))\left(\phi_{1}-\phi_{2}\right)\right)\right)
$$

with $K_{L i}$ being the reaction rate constant at the lithium electrode.

All the parameters of the cell are evaluated at $T=298 \mathrm{~K}$ for the reasons explained in [7]. The values of the standard cell potential, the self-interaction energies, and the kinetic parameters are

\begin{tabular}{|c|c|c|}
\hline Region & Value & Equation or boundary condition \\
\hline \multirow[t]{3}{*}{$x=L_{\mathrm{s}}+L_{1}$} & $y$ & $y=0$ \\
\hline & $C$ & $\epsilon_{\mathrm{s}} D_{\mathrm{eff}, \mathrm{s}} \nabla C=i_{\text {total }} / F$ \\
\hline & $i_{2}$ & $i_{2}=i_{\text {total }}$ \\
\hline \multirow[t]{4}{*}{$L_{\mathrm{s}}+L_{1}>x>L_{1}$} & $y$ & $y=0$ \\
\hline & $C$ & $\epsilon_{\mathrm{s}} \frac{\partial C}{\partial t}=\nabla\left(\epsilon_{\mathrm{s}} D_{\mathrm{eff}, \mathrm{s}} \nabla C\right)$ \\
\hline & $i_{2}$ & $i_{2}=i_{\text {total }}$ \\
\hline & $\eta$ & $\nabla \eta=\frac{i_{2}}{\sigma_{\mathrm{eff}, \mathrm{s}}}-\frac{\Re T\left(1-t_{+}^{0}\right)}{F C} \nabla C$ \\
\hline$x=L_{1}$ & $C$ & $\left.\epsilon_{\mathrm{s}} D_{\mathrm{eff}, \mathrm{s}} \nabla C\right|_{L_{1}+0}=\left.\epsilon_{1} D_{\mathrm{eff}, 1} \nabla C\right|_{L_{1}-0}$ \\
\hline \multirow[t]{2}{*}{$L_{1}>x>0$} & $y$ & For cylindrical particles (1) with (2)-(4), or (8) with (2)-(4); \\
\hline & $\begin{array}{l}C \\
i_{2}\end{array}$ & $\begin{array}{l}\text { For spherical particles (13) with (2)-(4), or (14) with (2)-(4). } \\
\qquad \begin{array}{c}\epsilon_{1} \frac{\partial C}{\partial t}=\nabla\left(\epsilon_{1} D_{\text {eff }, 1} \nabla C\right)+a\left(1-t_{+}^{0}\right) j_{n}^{+} \\
\nabla i_{2}=a F j_{n}^{+}\end{array}\end{array}$ \\
\hline \multirow{3}{*}{$x=0$} & $\eta$ & $\nabla \eta=\frac{-i_{\mathrm{total}}}{\sigma_{\mathrm{eff}}}+i_{2}\left(\frac{1}{\sigma_{\mathrm{eff}}}+\frac{1}{\sigma_{\mathrm{eff}, 1}}\right)-\frac{\Re T\left(1-t_{+}^{0}\right)}{F C} \nabla C$ \\
\hline & $C$ & $\epsilon_{1} D_{\mathrm{eff}, 1} \nabla C=0$ \\
\hline & $i_{2}$ & $i_{2}=0$ \\
\hline
\end{tabular}
given in table 1.

The corresponding set of equations from table 2 has been solved numerically.

Table 2. System of model equations and boundary conditions. 
Let us clear up how the speed of changing of $j_{n}^{+}$during the cycling depends on the speed of the change of the applied voltage $U_{\text {app }}$. We have, approximately,

$$
\begin{aligned}
\frac{\mathrm{d}}{\mathrm{d} t} j_{n}^{+}= & K C^{\beta-1}\left[(\beta-1)\left(1-\left.y\right|_{R=1}\right)-\beta\left(\left.y\right|_{R=1}\right)\right]\left(\left(1-\left.y\right|_{R=1}\right)\right)^{\beta-2}\left(\left.y\right|_{R=1}\right)^{\beta-1} \\
& \times\left\{\exp \left[\frac{(1-\beta) F}{\Re T}\left(U_{\mathrm{app}}-U\right)\right]-\exp \left[\frac{-\beta F}{\Re T}\left(U_{\mathrm{app}}-U\right)\right]\right\} \frac{\mathrm{d} y}{\mathrm{~d} t}+ \\
& +K C^{\beta-1} \frac{F}{\Re T}\left(\left(1-\left.y\right|_{R=1}\right)\right)^{\beta-1}\left(\left.y\right|_{R=1}\right)^{\beta}\left\{(1-\beta) \exp \left[\frac{(1-\beta) F}{\Re T}\left(U_{\mathrm{app}}-U\right)\right]+\right. \\
& \left.+\beta \exp \left[\frac{-\beta F}{\Re T}\left(U_{\mathrm{app}}-U\right)\right]\right\}\left[\frac{U_{\mathrm{app}}}{\mathrm{d} t}-U^{\prime} \frac{\mathrm{d} y}{\mathrm{~d} t}\right] .
\end{aligned}
$$

Substituting for $\frac{\mathrm{d} y}{\mathrm{~d} t}$ its expression from the diffusion equation in which we neglect electrostatic interaction, and substituting 1 for $y$ and its spacial derivatives, since they are dimensionless magnitudes, we get the following estimate for the order of magnitude:

$$
\frac{\mathrm{d}}{\mathrm{d} t} j_{n}^{+} \simeq j_{n}^{+}\left(1+\sum_{s=2}^{7} \frac{\Omega_{\mathrm{s}}}{\Re T}\right) \frac{D_{\mathrm{s}}}{R_{\mathrm{s}}^{2}} \pm j_{n}^{+}\left\{\frac{\beta F}{\Re T} \frac{d U_{\mathrm{app}}}{\mathrm{d} t}-\beta\left(1+\sum_{s=2}^{7} \frac{\Omega_{\mathrm{s}}}{\Re T}\right)^{2} \frac{D_{\mathrm{s}}}{R_{\mathrm{s}}^{2}}\right\}
$$

where we take "+" when $j_{n}^{+}$is positive, and "-" when it is negative. Hence, we can conclude that the steeper is the relation graph of $j_{n}^{+}$vs. the applied voltage, and the stronger is the following inequality

$$
\left|\frac{\mathrm{d} U_{\text {app }}}{\mathrm{d} t}\right| \gg \frac{\Re T}{F}\left(1+\sum_{s=2}^{7} \frac{\Omega_{\mathrm{s}}}{\Re T}\right)^{2} \frac{D_{\mathrm{s}}}{R_{\mathrm{s}}^{2}}
$$

the more effective is hysteresis.

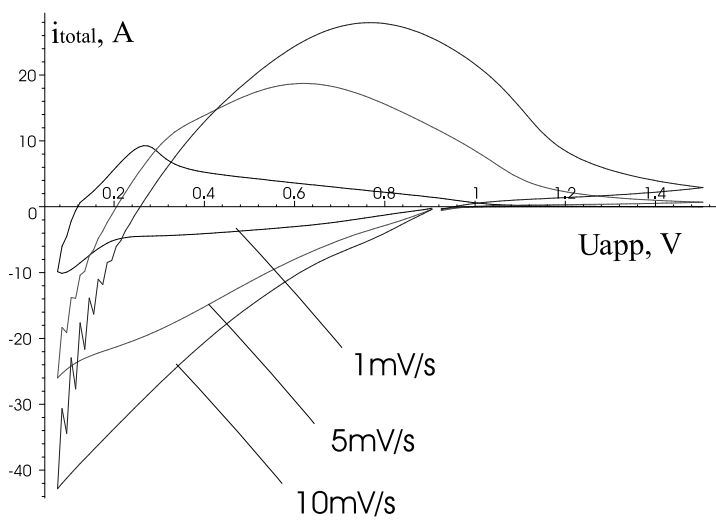

Figure 4. Comparison of current density $\left(\mathrm{A} / \mathrm{m}^{2}\right)$ vs. the applied voltage $(\mathrm{V})$ at scan rates $10 \mathrm{mV} / \mathrm{s}, 5 \mathrm{mV} / \mathrm{s}$ and $1 \mathrm{mV} / \mathrm{s}$ for cylindrical particles for chemical potential model with electric field.

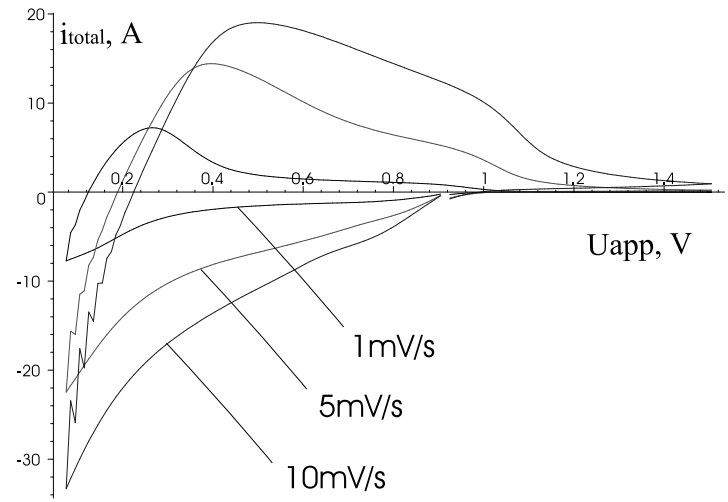

Figure 5. Comparison of current density $\left(\mathrm{A} / \mathrm{m}^{2}\right)$ vs. the applied voltage $(\mathrm{V})$ at scan rates $10 \mathrm{mV} / \mathrm{s}, 5 \mathrm{mV} / \mathrm{s}$ and $1 \mathrm{mV} / \mathrm{s}$ for spherical particles for chemical potential model with electric field.

And vice versa, the stronger is the reverse inequality

$$
\left|\frac{\mathrm{d} U_{\mathrm{app}}}{\mathrm{d} t}\right| \ll \frac{\Re T}{F}\left(1+\sum_{s=2}^{7} \frac{\Omega_{\mathrm{s}}}{\Re T}\right)^{2} \frac{D_{\mathrm{s}}}{R_{\mathrm{s}}^{2}}
$$


the less effective is hysteresis, (in this case $\frac{\mathrm{d}}{\mathrm{d} t} j_{n}^{+}$does not become large, because the whole righthand side in (10) is multiplied by the derivative of $y$ with respect to radial distance, which is small, since the concentration profile is sloping). The above mentioned is verified by figures 4 and 5 .

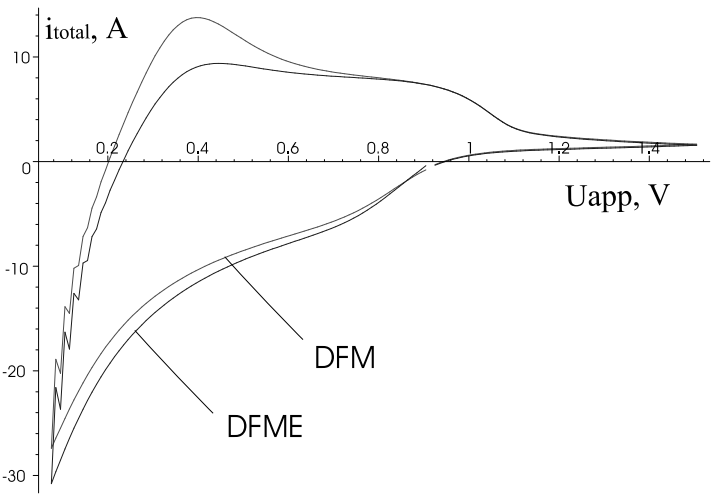

Figure 6. Current density $\left(\mathrm{A} / \mathrm{m}^{2}\right)$ vs. the applied voltage $(\mathrm{V})$ at scan rate $10 \mathrm{mV} / \mathrm{s}$ for cylindrical particles for purely diffusive model with (DFME) and without electric field (DFM).

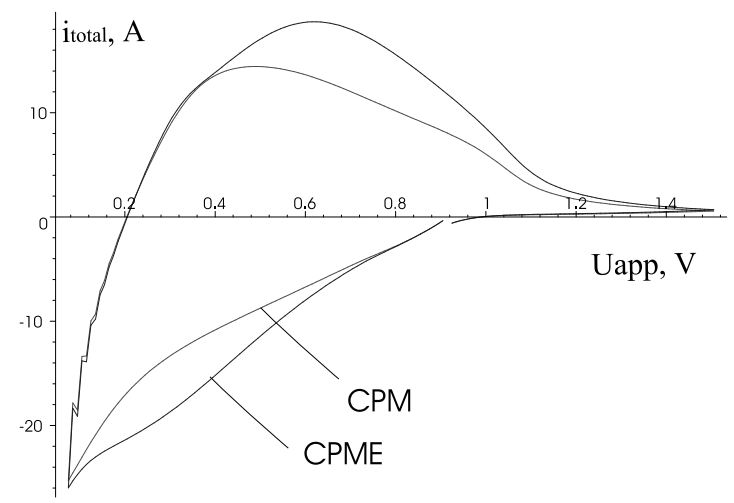

Figure 8. Current density $\left(\mathrm{A} / \mathrm{m}^{2}\right)$ vs. the applied voltage $(\mathrm{V})$ at scan rate $5 \mathrm{mV} / \mathrm{s}$ for cylindrical particles for chemical potential model with (CPME) and without electric field (CPM).

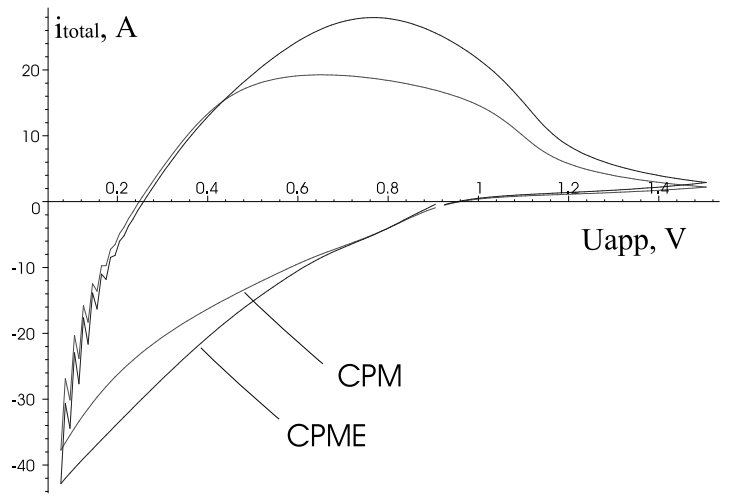

Figure 7. Current density $\left(\mathrm{A} / \mathrm{m}^{2}\right)$ vs. the applied voltage (V) at scan rate $10 \mathrm{mV} / \mathrm{s}$ for cylindrical particles for chemical potential model with (CPME) and without electric field (CPM).

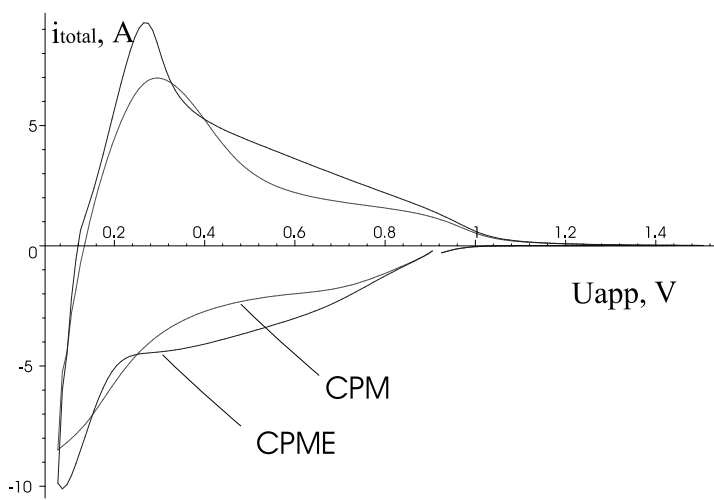

Figure 9. Current density $\left(\mathrm{A} / \mathrm{m}^{2}\right)$ vs. the applied voltage $(\mathrm{V})$ at scan rate $1 \mathrm{mV} / \mathrm{s}$ for cylindrical particles for chemical potential model with (CPME) and without electric field (CPM).

Though we do not consider this in the present paper, but numerical simulations suggest that hysteresis also depends on the size of particles of which the electrode is made. In order to reduce the irreversible losses and to make hysteresis less significant, the size of particles has to be diminished.

One can see from figure 6 that in the case of a constant diffusion coefficient, the graph of electrodynamic model lies below the graph of a purely diffusive model at the interval corresponding to the discharge of a cell, and is above the latter at large values of the applied voltage. This is due to the fact that the presence of a negative charge distributed inside the particle enhances the insertion of lithium ions, while the positive charge enhances, correspondingly, their outlet. At the same time, the graph of electrodynamic model is below the graph of a purely diffusive model in the vicinity of zero because the concentration profile is more sloping in electrodynamic case during 
the switching of the regime. In the case of a variable diffusion coefficient, the graph of the model with electric field, as figures 7-9 show, is generally closer to the graph of chemical potential model than in the previous case, because the 'lithium ion'-'lithium ion' interactions governed by the activity coefficient promote a more uniform distribution of lithium ions inside a particle and make the term proportional to $\nabla y$ in $\operatorname{div} \sigma E$ in the diffusion equation not that significant. Comparison of figures 7-9 shows that the relative difference between electrodynamic and non-electrodynamic models becomes more significant as the sweep rate of the applied voltage decreases. It seems that the electric field has its stable contribution to $j_{n}^{+}$which becomes more pronounced with the suppression of hysteresis.

The saw-like oscillations in figures $6,7,8,14-16$ are due to a computational error and should vanish as we decrease the step of integration. But this surpasses our computational facilities.

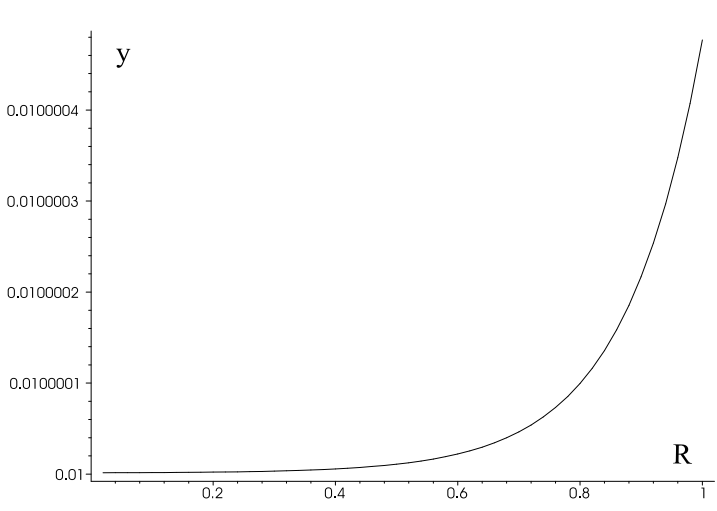

Figure 10. Profile of dimensionless concentration vs. dimensionless radial distance, i. e., the distance from the axis of symmetry of the particle, for cylindrical particles located at the distance $L_{1} / 2$ from current collector, for chemical potential model with electric field at the applied voltage $\mathrm{Uapp}=0.91489 \mathrm{~V}$.

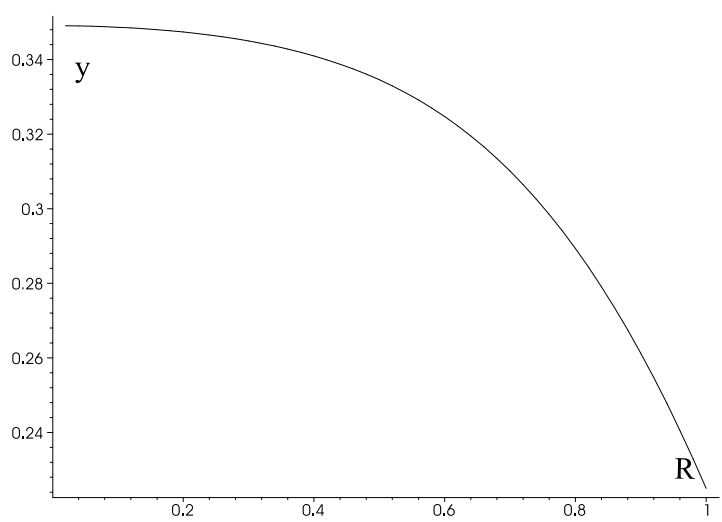

Figure 12. Profile of dimensionless concentration vs. dimensionless radial distance for cylindrical particles located at distance $L_{1} / 2$ from current collector, for chemical potential model with electric field at the applied voltage $\mathrm{Uapp}=0.51489 \mathrm{~V}$.

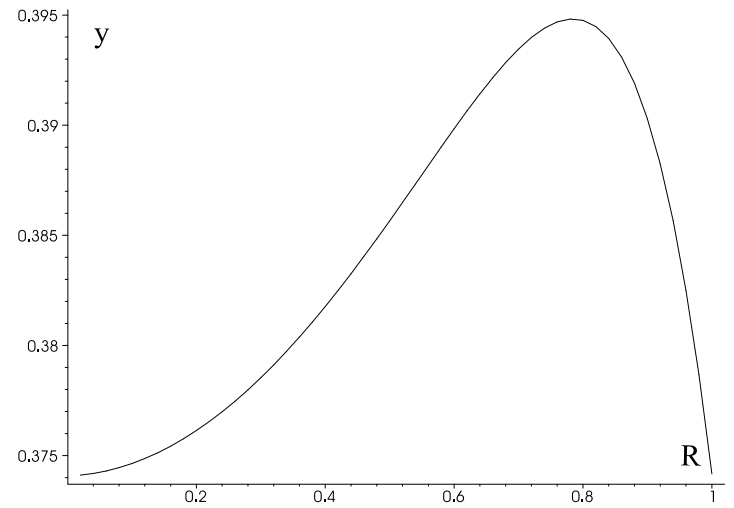

Figure 11. Profile of dimensionless concentration vs. dimensionless radial distance for cylindrical particles located at distance $L_{1} / 2$ from current collector, for chemical potential model with electric field at the applied voltage $\mathrm{Uapp}=0.31489 \mathrm{~V}$.

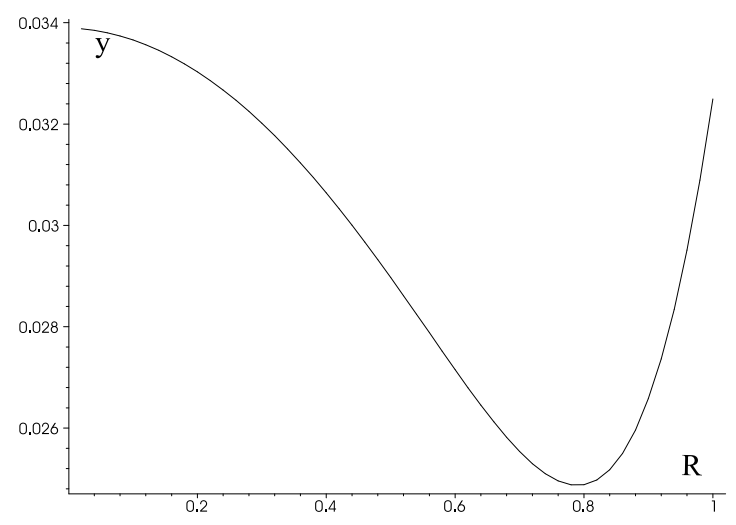

Figure 13. Profile of dimensionless concentration vs. dimensionless radial distance for cylindrical particles located at distance $L_{1} / 2$ from current collector, for chemical potential model with electric field at the applied voltage $\mathrm{Uapp}=0.81489 \mathrm{~V}$. 
Figures 10-13 show the profiles of dimensional concentration $y$ vs. dimensional radial distance $R$ at Stage 1, Stage 2, Stage 3, Stage 4 of the cycle, correspondingly. Figure 10 corresponds to the discharge of the cell and the lithium ions going inside the particle (intercalation). At this stage, ions are concentrated near the surface of the particle and their concentration decreases towards the center. Figure 11 corresponds to the switching of the regime, when we have stopped to discharge the cell and have begun to charge it. At this stage, lithium ion concentration still increases with radial distance, i. e., the distance from the axis of symmetry of the particle, near the center of the particle, takes on its maximum, and decreases with radial distance near the surface, where the process of the lithium ions outlet (deintercalation) has begun. Figure 12 corresponds to the charge, where the concentration is larger at the center of the particle and decreases with radial distance. Figure 13 corresponds to the switching of the regime. At this stage, we have ceased to charge the battery and have begun to discharge it again. The lithium ion concentration still decreases with radial distance near the center, takes on its minimum, and increases towards the surface, where intercalation (insertion) of lithium ions takes place.

\section{Spherical particles}

For spherical particles, equations (1) and (8) are replaced by

$$
\begin{aligned}
\frac{\partial y}{\partial \tau} & =\frac{1}{R^{2}} \frac{\partial}{\partial R}\left(R^{2} f(y) \frac{\partial y}{\partial R}\right) \\
\frac{\partial y}{\partial t} & =\frac{D_{\mathrm{s}}}{R_{\mathrm{s}}^{2}} \frac{1}{R^{2}} \frac{\partial}{\partial R}\left(R^{2} f(y) \frac{\partial y}{\partial R}\right)-\frac{1}{F C_{\mathrm{max}, \mathrm{s}}} \operatorname{div}(\sigma(y) E), \\
\operatorname{div}(E) & =\frac{3}{R_{\mathrm{s}} \sigma_{\mathrm{eff}, 1}} j_{n}^{+}-\delta \frac{F C_{\mathrm{max}, \mathrm{s}}}{\varepsilon_{0}}\left(y_{\mathrm{avr}}-y\right),
\end{aligned}
$$

where $\operatorname{div}(A(R))=\frac{1}{R^{2}} \frac{\partial}{\partial R}\left(R^{2} A(R)\right)$.

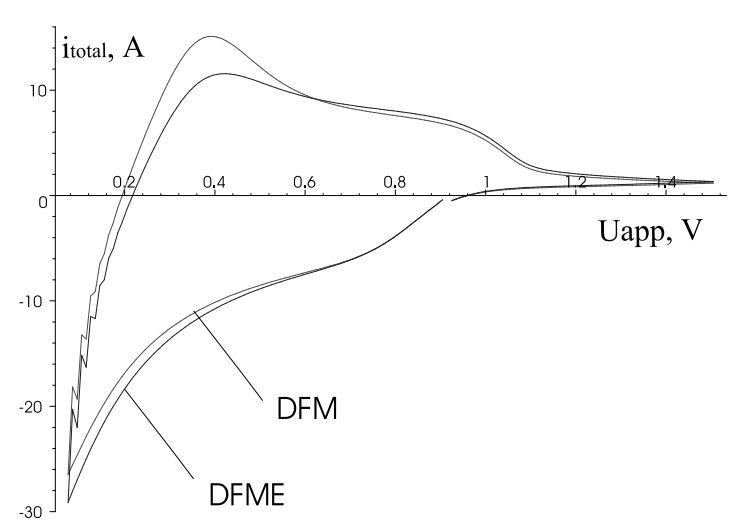

Figure 14. Current density $\left(\mathrm{A} / \mathrm{m}^{2}\right)$ vs. the applied voltage (V) at scan rate $10 \mathrm{mV} / \mathrm{s}$ for spherical particles for purely diffusive model with (DFME) and without electric field (DFM).

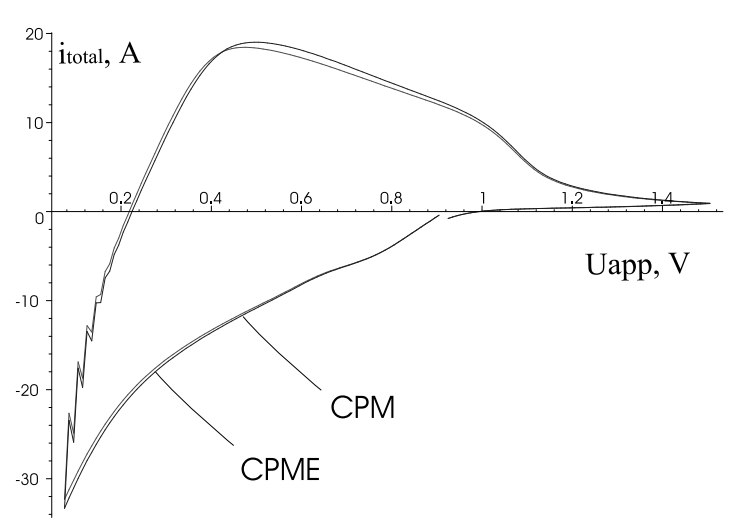

Figure 15. Current density $\left(\mathrm{A} / \mathrm{m}^{2}\right)$ vs. the applied voltage $(\mathrm{V})$ at scan rate $10 \mathrm{mV} / \mathrm{s}$ for spherical particles for chemical potential model with (CPME) and without electric field (CPM).

The corresponding set of equations from table 2 has been solved numerically.

In the same way as for cylindrical particles, figure 14 shows that in the case of a constant diffusion coefficient, the electrodynamic model admits lager discharge currents during the discharge, and at higher voltages during the charge. In the case of a variable diffusion coefficient, the model with electric field admits, in general, lager amplitudes of current in hysteresis, as figures 15-17 


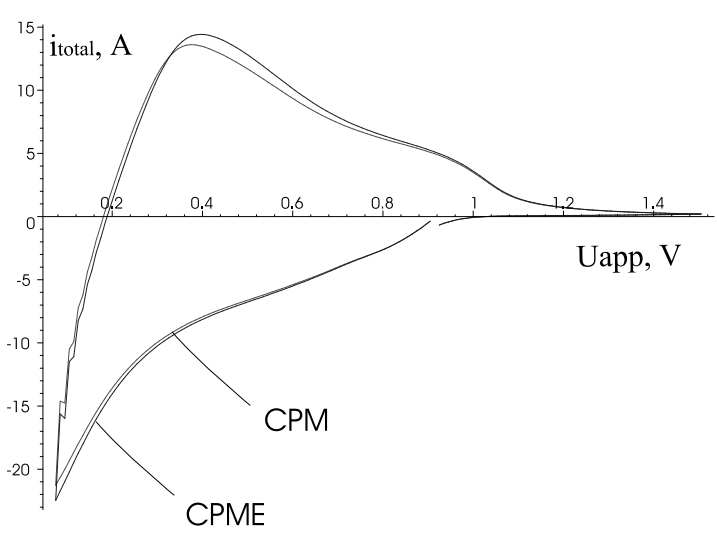

Figure 16. Current density $\left(\mathrm{A} / \mathrm{m}^{2}\right)$ vs. the applied voltage $(\mathrm{V})$ at scan rate $5 \mathrm{mV} / \mathrm{s}$ for spherical particles for chemical potential model with (CPME) and without electric field (CPM).

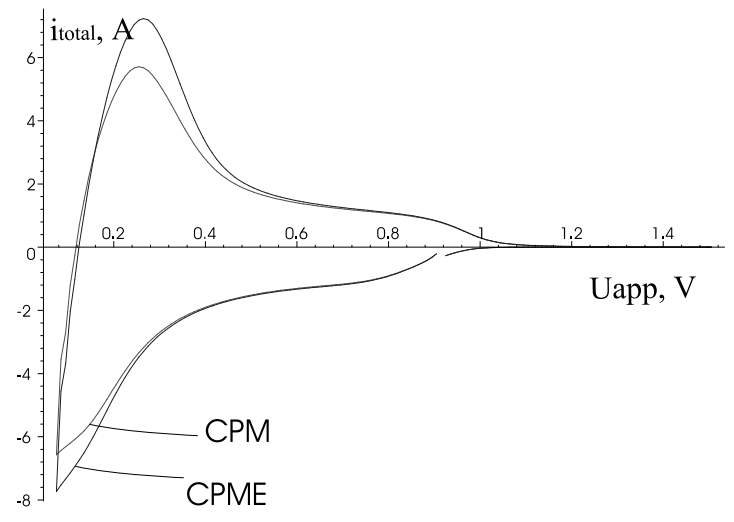

Figure 17. Current density $\left(\mathrm{A} / \mathrm{m}^{2}\right)$ vs. the applied voltage (V) at scan rate $1 \mathrm{mV} / \mathrm{s}$ for spherical particles for chemical potential model with (CPME) and without electric field (CPM).

show. In this case, the graphs of electrodynamic model lie closer to non-electrodynamic ones than in the previous. The relative difference between electrodynamic and non-electrodynamic models is more significant as the sweep rate of the applied voltage becomes smaller.

Comparing cyclic voltammograms for spherical (figures 15, 16, 17) and for cylindrical particles (figures 7-9) one may see that the effect of electrostatic field is more significant in the case of cylindrical particles because in that case the charge that produces this field occupies a larger part of a space.

\section{Conclusions}

We have made a simulation of the cycling of lithium cell with microporous carbon electrode under potentiodynamic control. We have compared the predictions of the models in which electric field is not considered (CPM, DFM) and the ones in which electrostatic interaction of lithium ions between each other and with the distribution of charge in the bulk of carbon electrode is taken into account (CPME, DFME). We have observed that there is a considerable difference between the results predicted by both models. The form of the particles does not have a significant effect on the predictions of both models. In the case of a constant diffusion coefficient, the electrodynamic model allows for lager discharge currents. In the case of a variable diffusion coefficient, the model with electric field allows for a lager sweep of current in general. The models without electric field predict steeper profiles of concentration of lithium ions inside the particle. The results indicate that the electrostatic interactions do matter, and the kinetic parameters obtained with the purely diffusive (DFM) or chemical potential model (CPM) may not represent the real kinetics of the system. 


\title{
References
}

1. Kovalyuk Z.D., Polyakov I.O., Dugaev V.K., Litvinov V.I., Russian Journal of Electrochemistry, 1997, 33, No. 1, 21-25.

2. Botte G.G., White R.E., J. Electrochem. Soc., 2001, 148, A54-A66.

3. Lee S.-I., Kim Y.-S., Chun H.-S., Electrochim. Acta, 2002, 47, 1055-1067.

4. Verbrugge M.W., Koch B.J., J. Electrochem. Soc., 1996, 143, 600.

5. Kanno R., Kawamoto Y., Takeda Y., Ohashi S., Imanishi N., Yamamoto O., Electrochem. Soc., 1992, 139, 3397.

6. Doyle M., Ph.D. Thesis. University of California, Berkeley, CA, 1995.

7. Johnson B.A., Botte G.G., White R.E., J. Electrochem. Soc., 1999, 146, 914.

\section{Моделювання циклічної роботи літієвої батареї 3 мікропористим вуглецевим електродом}

\author{
Д.В.Портнягін \\ Інститут фізики конденсованих систем НАН України, \\ 79011 Львів, вул. Свєнціцького, 1 \\ Отримано 23 квітня 2007 р., в остаточному вигляді - 17 вересня 2008 р.

\begin{abstract}
Чисельно моделювалися розрядно/зарядні цикли літієвої батареї із вуглецевим мікропористим електродом в режимі заданої напруги. Порівнювалися передбачення двох видів моделей: з постійним та змінним коефіцієнтом дифузії без врахування електростатичного поля, та з постійним та змінним коефіцієнтом дифузії з електростатичною взаємодією між іонами літію та із розподіленим зарядом всередині частинок вуглецевого електрода. Спостерігалася певна розбіжність між ними. Електростатична взаємодія сприяє інтеркаляції під час розрядки батареї та деінтеркаляції під час зарядки. Вивчалася залежність вираженості гістерезису від швидкості зміни прикладеної напруги. Гістерезис проявляється тим більше, чим більша швидкість прикладеної напруги. Було також отримано профілі концентрації на різних стадіях процесу розрядки/зарядки.
\end{abstract}

Ключові слова: літієва батарея, пористий електрод, потенціометрія

PACS: 82.47.Aa, 82.45.Gj, 82.45.Fk, 82.45.-h, 82.20.Wt 